\title{
SPECTRUM OF RHEUMATOID ARTHRITIS PATIENTS PRESENTING TO A TERTIARY CARE HOSPITAL IN PAKISTAN
}

\author{
Muhammad Khan, Muhammad Salman Mushtaq, Babur Salim, Sumera Mushtaq, Haris Gul, Saba Samreen
}

Fauji Foundation Hospital, Rawalpindi Pakistan

\begin{abstract}
Objective: To describe the demographic, clinical, serological and radiological scores in patients with rheumatoid arthritis (RA) presenting in a tertiary hospital in Pakistan.

Study Design: Cross sectional study.

Place and Duration of Study: Department of Rheumatology, Fauji Foundation Hospital (FFH), Rawalpindi, from Sep 2018 to Feb 2019.

Methodology: The study included 52 female patients with RA between the ages of 18 and 80 years. Data were obtained from FFH Rawalpindi's outpatient department. Demographic details, reference data, and serological status were recorded. The joints involved in the onset of the disease, joint deformities, clinical disease activity index (CDAI) and overall functional status were evaluated. Extra-articular manifestations of rheumatoid arthritis have also been examined during a detailed physical examination. The patient's bone mineral density was calculated by the use of dual energy absorptiometry (DEXA scan). Radiological scores were evaluated using modified sharp score.

Results: Mean age of the patient was $55.08 \pm 8.79$ and mean duration of disease $9.73 \pm 7.54$. The most common co-morbidity in rheumatoid arthritis patients was hypertension 20 (38.5\%). Twenty four (11.7\%) patients had osteoporosis. Wrist was the first joint involved in $17(32.7 \%)$ patients. Ulnar deviation was the most common deformity in 12 (23.1\%) patients. Sharp score for joint space narrowing was $61.09 \pm 36.90$ and sharp score joint erosions were $36.90 \pm 42.41$. Most common extra articular manifestation was anemia.

Conclusion: Rheumatoid arthritis as a variable spectrum of disease with different manifestations. Patients had radiological damage as demonstrated by high sharp score even before starting the appropriate treatment.
\end{abstract}

Keywords: Rheumatoid arthritis, Sharp score, Spectrum in rheumatoid arthritis.

This is an Open Access article distributed under the terms of the Creative Commons Attribution License (https://creativecommons.org/licenses/by-nc/4.0/), which permits unrestricted use, distribution, and reproduction in any medium, provided the original work is properly cited.

\section{INTRODUCTION}

Rheumatoid arthritis (RA) is a lifelong debilitating disease which is progressive and it leads to synovitis of joints and deformities if left untreated. Along with articular symptoms it is also associated with many extra articular manifestations. RA has an enormous impact on the quality of life and may also lead to early death due to the increased cardiovascular risk ${ }^{1}$. Worldwide incidence of RA is $0.5-1 \%{ }^{1,2}$. According to a study done in year 1998 in Pakistan the prevalence of RA in Pakistan has been reported to be around $0.5 \%{ }^{3}$. RA mostly presents with pain in small joints of the hands involving the metacarpo-phalangeal joints, proximal inter-phalangeal joints, wrists, elbows and shoulders. Some of the patients initially have a single joint involved which then leads to polyarticular involvement. A few patients have recurrent attacks of joint inflammation, the palindromic rheumatism before the symptoms of chronic illness. Apart from articular symptoms a number of extra articular manifestations are also seen In RA patients. Although they are less comm-

Correspondence: Dr Muhammad Salman Mushtaq, Department of Rhematology, Fauji Foundation Hospital, Rawalpindi Pakistan Received: 30 May 2019; revised received: 09 Nov 2019; accepted: 20 Nov 2019 only seen in our population but manifestations like anemia, interstitial lung disease, rheumatoid nodules, secondary sjogren, episcleritis are more seen as compared to other complications ${ }^{2}$.

Patients are diagnosed on the basis of typical history of pain in small joints of hands along with early morning stiffness $>30$ minutes. On musculoskeletal examination, there is evidence of synovitis of multiple joints in a symmetrical fashion. Rheumatoid factor, Anti cyclic citrullinated peptide (anti CCP), erythrocyte sedimentation rate (ESR), C-reactive protein are done to support the diagnosis. American College of Rheumatology (ACR) 2010 criteria can be applied to diagnose early $\mathrm{RA}^{4}$. If symptoms of RA are not controlled or disease is active it may lead to joint destruction and deformities like swan neck deformity, boutonniere deformity, $Z$ deformity, dorsal subluxation. A number of disease modifying drugs are used to control joint inflammation in RA that includes synthetic disease modifying drugs like methotrexate, lefluonamide, hydroxychloroquine, sulphsalazine and minocycline. Another group of drugs known as biologics are also used in the treatment of RA. These biologics includes TNF inhibitors and non TNF inhibitors like IL-6 
inhibitors, CD-20 blockers. Tofacitinib and Barticinib are a new class of drugs which are Janus kinase inhibitors which are recently approved by Food and drug administration (FDA) for the management of RA. Muscoskeletal ultrasounds and color Doppler are gaining importance in last 10 years for diagnosing joint inflammation in rheumatoid arthritis as well as to see erosions when they are not very evident on x-rays. Another investigation modality are $\mathrm{x}$-rays which are used in established RA to support the diagnosis of RA especially in seronegative arthritis as well as in steroid masked RA when synovitis is not clinically evident. X-rays of hands and feet are also used to see joint deformities associated with long-standing disease. They are also useful in documenting the progression of RA and to find the response and efficacy of new disease modifying antirheumatic agents. Although not very helpful in early RA but in established RA they give us diagnostic as well as prognostic significant information ${ }^{5}$. A number of radiological score were developed mostly for research purposes to quantify joint damage in RA like global ordinal scale, modified sharp scoring system, modified Larsen scoring system. Out of these sharp score is the most extensively studied. It has two components joint space narrowing (JSN) and joint erosions 5,6 . For erosion score fourteen sites in the hands and six sites in the feet are seen while for JSN thirteen sites in the hands and six sites in the feet is seen ${ }^{7,8}$. The erosions and joint space narrowing help the treating physician to see the response of a particular therapy. The main importance of these scores are for research purposes and their importance for changing or escalating medical therapy is somewhat not applicable in most of the cases. But they give clues about the aggressiveness of the diseases.

The objective of the study was to see the spectrum of RA presenting in a rheumatology unit of a tertiary care hospital. As it is not always necessary that RA presents with its typical features so therefore the aim of this outpatient hospital based study was to collect the information regarding diversity of the clinical, radiological and serological characteristics of the disease in Pakistan. Sharp radiological score was also calculated in all RA patients to assess radiological damage due to disease.

\section{METHODOLOGY}

This was a cross-sectional study conducted in the department of Rheumatology of the Fauji Foundation Hospital (FFH), Rawalpindi, from September 2018 to February 2019, after approval was taken by the ethics committee. Patients were selected by non-probability consecutive sampling and the patients' written consent was obtained. A total of 52 patients were selected and the sample size was calculated using the WHO sample size calculator $(24 \%$ of the expected population, absolute precision of $6 \%, 95 \%$ confidence interval). Patients diagnosed as RA cases were selected based on the 2010 ACR criteria. Patients between 18-80 years were enrolled. Patients who did not meet the above criteria were excluded from the study. Patients were evaluated at the start of the study. The demographic details of the patients, including age, gender, disease duration, and the drugs taken (synthetic or biological DMARDs) were noted in the proforma. Disease activity was assessed clinically by observing the number of tender joints (TJ), inflamed and swollen joints (SJ) and visual analogue score (VAS) for pain (0-10). The clinical disease activity index (CDAI) was calculated.

Serological tests including rheumatoid factor (RF) and Anti-CCP were noted from the hospital record to evaluate for seropositive or seronegative status. Patient's general physical examination was done to see for extra articular manifestations. Patient's DEXA scan was done and $T$ score of spine and hip was noted of patients $>40$ years and $Z$ score was noted for patients $<40$ years. X-rays of hands and feet were done and with the help of radiologist modified sharp score was calculated. Data was analyzed using SPSS-23. Mean and Standard deviation (SD) were calculated for numeric variables like age, duration of disease, $\mathrm{T}$ scores, and sharp scores. Percentages were calculated for seropositivity, osteoporosis, and involvement of joints, deformities, CDAI, extra articular manifestations and comorbidities.

\section{RESULTS}

In this study about 52 patients, all females were included with mean age \pm SD of $55.80 \pm 8.79$, with mean disease duration of $9.73 \pm 7.54,39 \%$ patients have seropositive RA. Wrist was the most common joint involved, ulnar deviation was the most common deformity. Anemia was the most common extraarticular manifestation while hypertension was the most common comorbidity in our population. The detailed results are shown in table.

\section{DISCUSSION}

RA is a long standing illness more accurately lifetime with high morbidity in the form of functional disability and pain, with premorbidities and extraarticular manifestations. Previously it was thought that RA was a joint disease without impact on the patients' 
systems but it was found to be a multisystemic disease involving many systems apart from joints.

Table: Demographic, clinical, serological and radiological details of patients with rheumatoid arthritis.

\begin{tabular}{|c|c|}
\hline Parameters & $\mathrm{n}(\%)$ \\
\hline Total sample size & $\mathrm{n}=52$, (females) \\
\hline Age(years) (Mean \pm SD) & $55.80 \pm 8.79$ \\
\hline $\begin{array}{l}\text { Number of years from disease diagnosis } \\
(\text { Mean } \pm \text { SD) }\end{array}$ & $9.73 \pm 7.54$ \\
\hline T score at hip (Mean \pm SD) & 0.78 \\
\hline T score at spine (Mean \pm SD) & 0.68 \\
\hline \multicolumn{2}{|c|}{ Sharp radiological score hands and feet (Mean \pm SD) } \\
\hline Sharp score joint space narrowing & $61.09 \pm 36.90$ \\
\hline Sharp score joint erosions & $36.90 \pm 42.41$ \\
\hline Married & $45(86.5 \%)$ \\
\hline $\begin{array}{l}\text { Seropositive } \\
\text { (Either RA or Anti CCP positive) } \\
\text { Seronegative } \\
\text { (Both RA factor and Anti CCP negative) }\end{array}$ & $\begin{array}{l}39(75 \%) \\
13(25 \%) \\
\end{array}$ \\
\hline Osteoporosis & $22(42.3 \%)$ \\
\hline \multicolumn{2}{|c|}{ Joint first involved at the time of RA presentation } \\
\hline Wrists & $17(32.7 \%)$ \\
\hline Proximal Interphalangeal Joints (PIP) & $15(28.8 \%)$ \\
\hline Metacarpophalangeal Joint (MCP) & $12(23.1 \%)$ \\
\hline Elbows & $6(11.5 \%)$ \\
\hline Shoulders & - \\
\hline Knees & $1(1.9 \%)$ \\
\hline Foot & $1(1.9 \%)$ \\
\hline \multicolumn{2}{|l|}{ Deformities } \\
\hline Ulnar deviation & $12(23.1 \%)$ \\
\hline Z deformity & $7(13.5 \%)$ \\
\hline Button Hole deformity & $4(7 \%)$ \\
\hline Dorsal subluxation of & \\
\hline Metacarpophalangeal Joint (MCP) & $5(9.6 \%)$ \\
\hline Swan neck deformity & $1(1.9 \%)$ \\
\hline Multiple deformities & $5(9.6 \%)$ \\
\hline No deformity & $18(34.6 \%)$ \\
\hline \multicolumn{2}{|l|}{ Clinical Disease Activity Index (CDAI) } \\
\hline Remission & $12(23.1 \%)$ \\
\hline Low & $19(36.5 \%)$ \\
\hline Moderate & $13(25 \%)$ \\
\hline High & $8(15.4 \%)$ \\
\hline Use of steroids $(5-7.5 \mathrm{mg})$ & $33(63.5 \%)$ \\
\hline History of intra-articular injection & $21(40.4 \%)$ \\
\hline \multicolumn{2}{|l|}{ Medications taking } \\
\hline Methotrexate & $12(23.1 \%)$ \\
\hline Lelunamide & $2(3.8 \%)$ \\
\hline Hydroxycholorquine & $1(1.9 \%)$ \\
\hline Sulphasalazine & - \\
\hline Combination Disease-Modifying & \\
\hline Antirheumatic Drugs (DMARDs) & $37(71.2 \%)$ \\
\hline \multicolumn{2}{|l|}{ Biologics taken } \\
\hline Rituximab & $2(3.84 \%)$ \\
\hline Tociluzimab & - \\
\hline \multicolumn{2}{|c|}{$\begin{array}{l}\text { Intolerant to Disease-Modifying Antirheumatic Drugs } \\
\text { (DMARDs) }\end{array}$} \\
\hline Methotrxate & $15(28.4 \%)$ \\
\hline Lefulonamide & $11(21.15 \%)$ \\
\hline Hydroxycholoroquine & $1(1.9 \%)$ \\
\hline Sulphsalazine & $2(3.8 \%)$ \\
\hline No intolerance & $23(44.23 \%)$ \\
\hline
\end{tabular}

\begin{tabular}{l|c}
\hline \multicolumn{2}{l}{ Rheumatoid Arthritis Functional Status } \\
\hline I & $25(48.1 \%)$ \\
II & $19(36.5 \%)$ \\
III & $5(9.6 \%)$ \\
IV & $3(5.8 \%)$ \\
\hline \multicolumn{2}{l}{ Extraarticular Manifestations } \\
\hline Anemia & $15(28.84 \%)$ \\
Secondary Sjogren syndrome & $12(23.07 \%)$ \\
Thrombocytosis & $8(15.38 \%)$ \\
Interstitial lung disease & $5(9.61 \%)$ \\
Rheumatoid nodules & $2(3.84 \%)$ \\
Sensory neuropathy & $2(3.84 \%)$ \\
Vasculitis & $1(1.9 \%)$ \\
None & $7(13.46 \%)$ \\
\hline Co-Morbidities & $20(38.5 \%)$ \\
\hline Hypertension & $7(13.5 \%)$ \\
Diabetes & $6(11.5 \%)$ \\
Hepatitis C & $2(3.8 \%)$ \\
Thyroid disorder & $1(1.9 \%)$ \\
Ischemic heart disease & $3(5.8 \%)$ \\
Diabetes plus hypertension &
\end{tabular}

Faisal Al Tamimi at Nizwa Hospital, Oman conducted a study on 66 patients with RA. Out of $57.7 \%$ of patients were seropositive, while in our study $75 \%$ were seropositive. The most frequent extra-articular manifestation was $27.7 \%$ anemia after that dry eyes and dry mouth $(24.42 \%)$. The joints of the upper limbs were involved more often than the lower limbs and the most involved joint was the wrist $(81 \%)$, followed by the metacarpophalangeal joints (MCP) $(66.66 \%)$, the knee $(57.57 \%)$, the ankle $(45.45 \%)$, the elbow $(42.42 \%)$, the shoulder $(42.42 \%)$ and the proximal interphalangeal joints (PIP) (36.36\%). The most common comorbidity found in RA patients was hypertension (21\%) followed by ischemic heart disease $(13.63 \%)$ and diabetes mellitus $(9.03 \%)^{9}$. While in our study, anemia and keratoconjuctivitis sicca were the most common extra-articular manifestations like the statistics in the Oman study. The wrist was the most common joint affected and hypertension was the most common comorbidity associated with RA similar to the Oman study.

Another study conducted at Al-Amiri Hospital in Kuwait showed that there were extra-articular manifestations in 24 patients; the most common was the Sicca complex in 14 patients. We found seropositive RA in 60 patients and joint destruction with erosions in 42 patients $^{10}$.

It was also observed that Pakistani and Indian patients with RA had a lower percentage of rheumatoid nodules and lesser X-ray erosions in the hands and feet as compared to British population in the studies conducted by Hameed and Gibson in 1996, about $30 \%$ population of British have rheumatoid nodules 
as compared $3-4 \%$ in our study 11,12 , the extra articular manifestations apart from joint symptoms were less in our population than the western population, like 13\% in Indian population and about $30 \%$ in western population $^{13,14}$.

Comorbidities are also associated with RA probably due to premature atherosclerosis. Another study conducted in RA in 2018 at Rawalpindi local hospital showed hypertension as the most common comorbidity with percentage of about $40 \% 15,16$.

Modified sharp score is measured to demonstrate the effect of treatment on joints of patients of RA and psoriatic arthritis 7,18 . But even if patients were taking DMARDs they have high sharp scores. The reason behind this may be the less use of biologic DMARDs in our setup as only two patients were given rituximab for high disease. Another reason may be that most of the patients lies in low to moderate group and even with treatment, remission is not achieved so clinical as well as subclinical damage to joints continues which leads to increase in sharp score in these patients. JSN score is higher in most patients than the erosions score ${ }^{17}$.

Identification of extra articular symptoms also helps the treating physician to aggressively treat the articular symptoms along with proper management of anemia, sjogren and ILD ${ }^{18}$. High sharp scores indicates that target of the treating rheumatologist is to lower the disease activity of all patients to remission or low disease activity either by the use of biologic DMARDS or aggressively escalating the synthetic DMARDs ${ }^{19,20}$.

\section{LIMITATIONS OF THE STUDY}

This study had some limitations that included a limited duration, a non-probability sampling technique, a comparison group and an acute long-term follow-up score not performed. The study had only samples that contained females, as was done in a hospital made for the families of former soldiers. The sample may not be a representative of our population in general, but it could be a representative of the female population of our country. The correlation between disease activity was not observed with seropositivity and sharp score. The study could have been done in a different large setup or two or three other setups and a comparison group can also be included to make it a comparative study.

\section{CONCLUSION}

RA has a wide spectrum of clinical and serological changes in the disease, along with a series of extra- articular manifestations such as anemia, secondary sjogren's syndrome and interstitial lung disease. Xrays of the hands and feet capture the initial process of RA development (erosion of the MTP and therefore of other joints). Changes in PIP, MCP, MTP, IP and wrist joints provide a good indication of the evolution of RA.

\section{CONFLICT OF INTEREST}

This study has no conflict of interest to be declared by any author.

\section{REFERENCES}

1. Johannes WJ. Bijlsma and Eric Hachulla. EULAR textbook on rheumatic diseases. $3^{\text {rd }}$ edition. London: BMJ: Saudi Med J 2015; 36(12): 1503-1508.

2. Firestein GS, Budd RC, Gabriel SE, McInnes IB, O'Dell JR. Kelly's text book of rheumatology. 10 $0^{\text {th }}$ ed. St Louis: WB Saunders 2016 [Internet] Avalible at: https://www.elsevier.com/books/ kelleys-textbook-of-rheumatology/9781437717389.

3. Farooqi AZ, Gibson T. Prevalence of major rheumatic disorders in the adult population of northern Pakistan. Brit J Rheum 1998; 37(5): 491-95.

4. Aletaha D, Neogi T, Silman AJ, Funovits J, Felson DT, Bingham $\mathrm{CO}$, et al. rheumatoid arthritis classification criteria: an American College of Rheumatology/European League Against Rheumatism collaborative initiative. Ann Rheum Dis 2010; 69(9): 1580-88.

5. Quintana-Duque MA, Rondon-Herrera F, Mantilla R, Calvo Paramo E, Yunis JJ, Varela-Narino A, et al. Predictors of remission, erosive disease and radiographic progression in a Colombian cohort of early onset rheumatoid arthritis: a 3-year follow-up study. Clin Rheumatol 2016; 35(6): 1463-73.

6. Jew NB, Hollins AM, Mauck BM, Smith RA, Azar FM, Miller RH, et al. Reliability testing of the Larsen and Sharp classifications for rheumatoid arthritis of the elbow. J Shoulder Elbow Surg 2017; 26(1): 140-43.

7. Charles G, Peterfy, Chun Wu, Jan Szechinskietal. Comparison of the Genant-modified Sharp and van der Heijde-modified Sharp scoring methods for radiographic assessment in rheumatoid arthritis. Int J Clin Rheumatol 2011; 6(1): 15-24.

8. Sokka T. Radiographic scoring in rheumatoid arthritis: a short introduction to the methods. Bull Nyu Hosp Jt Dis 2008; 66(2): $166-68$.

9. Temimi FA. The spectrum of rheumatoid arthritis attending rheumatology clinic in Nizwa Hospital. Oman Med J 2010; 25(3): 184-89.

10. Al-Salem IH, Al-Awadhi AM. The expression of rheumatoid arthritis in kuwaiti patients in an outpatient hospital-based practice. Med Princ Pract 2004; 13(1): 47-50.

11. Hameed K, Gibson T. A comparison of the clinical features of hospital out-patients with rheumatoid disease and osteoarthritis in Pakis-tan and England. Br J Rheumatol 1996; 35(10): 994-99.

12. Ziemer M, Müller AK, Hein G, Oelzner P, Elsner P. Incidence and classification of cutaneous manifestations in rheumatoid arthritis. J Dtsch Dermatol Ges 2016; 14(12): 1237-46.

13. Cojocaru M, Cojocaru IM, Silosi I, Vrabie CM, Tanasescu R. extra-articular manifestations in rheumatoid arthritis. Maedica (Buchar) 2010; 5(4): 286-91.

14. Chandrashekara S, Shobha V, Dharmanand BG, Jois R, Kumar S, Mahendranth KM, et al. Reduced incidence of extra-articular manifestations of RA through effective disease control: Karnataka Rheumatoid Arthritis Comorbidity (KRAC) study. Int J Rheum Dis 2017; 20(11): 1694-1703. 
15. Muhammad M, Babur S, Saba S, Amjad N, Haris G. Risk of cardiovascular disease in patients of rheumatoid arthritis (RA) presenting in a tertiary care hospital of Pakistan. Pak Armed Forces Med J 2018; 68(6): 1691-95.

16. Syed A, Aneela K, Syed J. Epidemiology of Rheumatoid Arthritis in a tertiary care unit, Karachi, Pakistan. Pak Med Assoc 2011; 61(2): 123-26.

17. Takeshi M, Koichiro Y, Katsunori I, Ryo H, Mina I, Ken O. Relationship of callosities of the forefoot with foot deformity, health assessment questionnaire disability index, and joint damage score in patients with rheumatoid arthritis. Mod Rheumatol 2020; 30(2): 287-92.

18. Ravindren J, Cavill C, Balakrishen C, Jones SM, Korendowych E,
McHugh NJ. A modified sharp score demonstrates disease progression in established psoriatic arthritis. Arthritis Care Res 2010; 62(1): 86-91.

19. Markusse IM, Akdemir G, Dirven L, Goekoop-Ruiterman YPM, Van Groenendael JHLM, Han KH. Long-term outcomes of patients with recent-onset rheumatoid arthritis after 10 years of tight controlled treatment: a randomized trial. Ann Intern Med 2016; 164(8): 523-31.

20. Steunebrink LMM, Versteeg LGA, Vonkeman HE, Klooster PM, Van de Laar MAFJ. Radiographic progression in early rheumatoid arthritis patients following initial combination versus stepup treat-to-target therapy in daily clinical practice: results from the DREAM registry. BMC Rheumatol 2018; 2(1): 1-10. 